\section{RESEARCH ARTICLE 10.1029/2018JC014042 \\ The Structure and Entrainment Characteristics of Partially Confined Gravity Currents}

Key Points:

- In partially confined settings, channel depth is a key control on the height of a gravity current's velocity maximum

- Both streamwise and overbank discharge rates can rapidly adjust downstream, with evidence of flow tuning and equilibration

- The entrainment coefficient of a partially confined flow is similar to that of a fully confined flow with the same Richardson number

Supporting Information:

- Supporting Information S1

Correspondence to:

R. W. Kelly,

scrk@leeds.ac.uk

Citation:

Kelly, R. W., Dorrell, R. M., Burns, A. D., \& McCaffrey, W. D. (2019). The structure and entrainment characteristics of partially confined gravity currents. Journal of Geophysical Research: Oceans, 124, 2110-2125. https://doi.org/10.1029/2018JC014042

Received 3 APR 2018

Accepted 20 FEB 2019

Accepted article online 22 FEB 2019

Published online 28 MAR 2019

(C)2019. American Geophysical Union. All Rights Reserved.

\author{
R. W. Kelly ${ }^{1}$ (D), R. M. Dorrell ${ }^{2}$ (D), A. D. Burns ${ }^{3}$, and W. D. McCaffrey ${ }^{4}$ \\ ${ }^{1}$ EPSRC Centre for Doctoral Training in Fluid Dynamics, University of Leeds, Leeds, UK, ${ }^{2}$ Energy and Environment \\ Institute, University of Hull, Kingston upon Hull, UK, ${ }^{3}$ School of Chemical and Process Engineering, University of Leeds, \\ Leeds, UK, ${ }^{4}$ School of Earth and Environment, University of Leeds, Leeds, UK
}

Abstract Seafloor channels are the main conduit for turbidity currents transporting sediment to the deep ocean, and they can extend for thousands of kilometers along the ocean floor. Although it is common for channel-traversing turbidity currents to spill onto levees and other out-of-channel areas, the associated flow development and channel-current interaction remain poorly understood; much of our knowledge of turbidity current dynamics comes from studies of fully confined scenarios. Here we investigate the role that partial lateral confinement may play in affecting turbidity current dynamics. We report on laboratory experiments of partially confined, dilute saline flows of variable flux rate traversing fixed, straight channels with cross-sectional profiles representative of morphologies found in the field. Complementary numerical experiments, validated against high-resolution laboratory velocity data, extend the scope of the analysis. The experiments show that partial confinement exerts a first-order control on flow structure. Overbank and downstream discharges rapidly adjust over short length scales, providing a mechanism via which currents of varying sizes can be tuned by a channel and conform to a given channel geometry. Across a wide range of flow magnitudes and states of flow equilibration to the channel, a high-velocity core remains confined within the channel with a constant ratio of velocity maximum height to channel depth. Ongoing overbank flow prevents any flow thickening due to ambient entrainment, allowing stable downstream flow evolution. Despite dynamical differences, the entrainment rates of partially confined and fully confined flows remain comparable for a given Richardson number.

Plain Language Summary Turbidity currents are large, underwater flows that can travel for thousands of kilometers across the ocean floor. They carry huge volumes of sediment, causing them to be denser than seawater. It is this density difference that is their main driving force. Not only are they responsible for forming complex seafloor structures, but they can be highly destructive, capable of destroying any seafloor infrastructure in their path. Like rivers, turbidity currents often flow within channels. In this study we show how these channels play a key role in the structure of the currents and how they could be responsible for the vast distances the currents can travel.

\section{Introduction}

Seafloor channels are the main conduits through which turbidity currents transport sediment from the continental shelf to the deep ocean (Meiburg \& Kneller, 2010; Peakall \& Sumner, 2015). The submarine fans that they form are some of the largest sedimentary accumulations on Earth (Curray et al., 2002; Talling et al., 2007). Due to the inherent challenges the deep-water environment poses, only recently have direct field measurements become more widespread (Azpiroz-Zabala et al., 2017; Dorrell et al., 2014, 2016; Khripounoff et al., 2003; Sumner et al., 2013; Sumner \& Paull, 2014; Talling et al., 2013; Xu, 2010). In comparison there has been a long history of model development based on laboratory experiments (e.g., Ellison and Turner, 1957; Bonnecaze et al., 1993; Buckee et al., 2001; Garcia and Parker, 1993; Islam \& Imran, 2010; Keevil et al., 2006; Middleton, 1966; Straub et al., 2008; Sequeiros et al., 2010) and numerical simulations (e.g., Abd El-Gawad et al., 2012; Cantero et al., 2009; Dorrell et al., 2014; Eidsvik \& Brørs, 1989; Huang et al., 2005; Imran et al., 2004; Giorgio Serchi et al., 2011; Kneller et al., 2016).

The majority of these studies were conducted within fully confined channels. Yet the partially confined channel-levee component of natural systems usually extends much further than the fully confined canyons that feed them (Klaucke et al., 1998; Meiburg \& Kneller, 2010; Nakajima \& Kneller, 2013). Those studies that do consider unconfined/partially confined settings have been run over erodible beds (De Leeuw et al., 2016; 

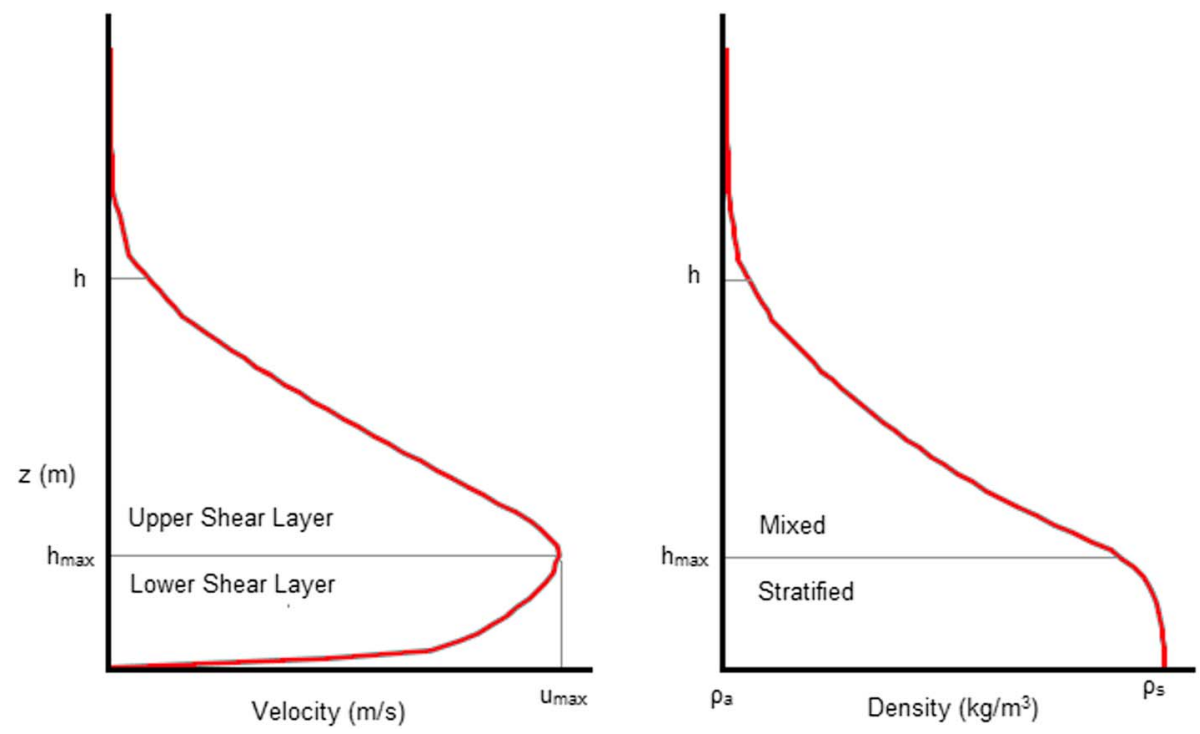

Figure 1. Velocity and density profiles for a gravity current generated by the release of a saline solution into an ambient fluid (water), as depicted in Figure 2. These are characterized by two shear layers separated by a velocity maximum. The lower shear layer is generated by basal drag and is stratified in nature, whereas the upper shear layer is a result of drag with the ambient fluid and is subsequently more mixed. The parameter $h$ is the height of the current defined by the Ellison and Turner (1959) method in Table $1, \rho_{a}$ and $\rho_{s}$ are the densities of the ambient and saline fluid, respectively, and $h_{\max }$ and $u_{\max }$ are the height and magnitude of the velocity maximum.

Mohrig \& Buttles, 2007; Straub et al., 2008) and tend to focus on morphological evolution and channel inception rather than flow dynamics. While such studies increase knowledge of channel and system development, the evolving channel geometries limit the consistency of flow data measured from successive currents.

The dynamics and behavior of partially confined flows, where the current can overspill onto the levees, are arguably far more complex and difficult to predict than for fully confined flows. Differing levels of confinement lead to changes in the ratios of ambient entrainment and overbank losses, but a systematic review of the flow field under a range of confinements is lacking. Mohrig and Buttles (2007) defined channelized, quasi-channelized, and unconfined regimes based on the advancement of the flow front but without presentation of detailed flow velocity or density data.

To date, it is fully confined studies that have been widely used to explain and predict the structure and properties of gravity currents. Parker et al. (1987) conducted straight channel experiments and reviewed previous experimental data to find a Richardson number-dependent expression for the entrainment coefficient of a flow,

$$
e_{w}=\frac{0.075}{\sqrt{1+718 \mathrm{Ri}^{2.4}}}
$$

The rate at which a flow entrains ambient fluid is a key factor in both its spatial and temporal development and could help to provide an explanation as to why turbidity currents can travel for thousands of kilometers (Meiburg \& Kneller, 2010). Kneller et al. (2016) used numerical simulations to show that, under certain conditions, turbidity currents can have a stably stratified upper shear layer (Figure 1) with little mixing and low velocity gradients, resulting in a reduction in ambient entrainment; when predicting flow characteristics the use of bulk variables to approximate local variables was also questioned (such as using the bulk Richardson number as a proxy for the gradient Richardson number, a measure of stratification stability). In another fully confined experiment, Sequeiros et al. (2010) observed a dependence of the velocity structure of the flow on the Richardson number, attributed to changes in stratification stability. The velocity profiles of subcritical flows $(R i>1)$ exhibited a velocity maximum close to the top of the flow, although a large bed roughness is likely to have caused this. This is in contrast to previously observed profiles where the outer shear layer 

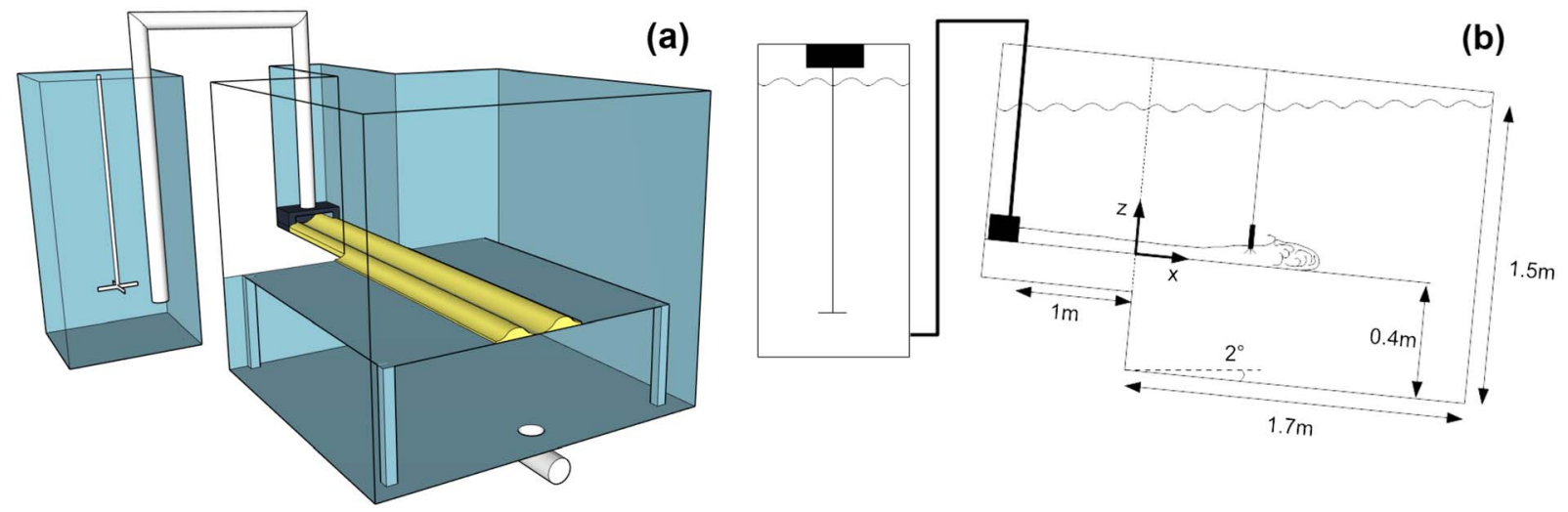

Figure 2. (a) A 3-D visualization (channel profile not to scale) and (b) a cross-sectional schematic of the setup employed in the Sorby Laboratory. Saline was pumped from a large mixing tank via a momentum diffuser into the main tank which was inclined at $2^{\circ}$. A 1-m long confined inlet channel allowed the flow to develop. The channel was elevated on a false floor to allow fluid to collect in a sump underneath. The frame of reference is defined relative to the channel, with the origin positioned on the channel thalweg at the entrance to the main tank.

is 5-10 times thicker than the inner layer (Meiburg \& Kneller, 2010). Additionally, Sequeiros (2012) suggested that channel morphology can be used to predict Richardson or Froude numbers and subsequently flow conditions. However, this approach has limitations for erosional or bypassing flows as it does not take into account Reynolds-dependent turbulent effects in the lower boundary (Imran et al., 2016). Also, high-velocity maximum heights were not replicated in the simulations of Kneller et al. (2016), despite the stably stratified layer, nor in further experiments of subcritical flows which found limited dependence on Richardson number (Stagnaro \& Pittaluga, 2014).

Regardless of the debate over confined-flow structure, the kinematics of a partially confined flow must be fundamentally different due to the occurrence of overspill. Here saline flow experiments have been conducted in a straight fixed channel with a channel-levee profile designed to be a realistic representation of morphology found in the field. Velocity data for a range of flow magnitudes has been captured (Table 2) with the aim of analyzing partially confined flow dynamics, entrainment characteristics, and flow evolution.

Additionally, numerical simulations using a RANS (Reynolds-averaged Navier-Stokes) model have been used both to extend the range of flow conditions that are possible in the laboratory and to produce data for the whole flow field.

\section{Method}

\subsection{Laboratory Setup}

A series of continuous release saline gravity current experiments were conducted in the Sorby Environmental Fluid Dynamics Laboratory at the University of Leeds. While saline currents do not allow for the study of particulate settling, they do provide a good dynamical model of turbulent and stratification effects in turbidity currents (Cossu \& Wells, 2012; Islam \& Imran, 2010; Kneller \& Buckee, 2000). The flume used measured $1.7 \mathrm{~m} \times 1.7 \mathrm{~m}$ and had a water depth of $1.5 \mathrm{~m}$. An additional 1-m long inlet channel, along which the currents developed, was centered on one side wall. The entire flume was inclined at an angle of $2^{\circ}$ downstream. A fiberglass channel model was placed on a suspended floor $0.4 \mathrm{~m}$ above the tank base, with the area underneath acting as a sump to collect denser than ambient fluid.

The channel model is $0.22 \mathrm{~m}$ wide and extended the entire length of the inlet channel and $1.5 \mathrm{~m}$ into the main flume. The channel-levee profile was designed specifically to create an environment that might replicate morphology found in the field. The channel itself was $0.0275 \mathrm{~m}$ deep, giving an aspect ratio of 8 , and the channel profile took the form of a sine curve to give a maximum slope of $22^{\circ}$ on the channel sides (Figure 3 ). Channel size and width/depth ratio were chosen to balance the need for deep enough flows to be fully turbulent, while achieving a low aspect ratio as is often seen in the field (Clark et al., 1992; Kenyon et al., 1995). The channel is bounded by a $22-\mathrm{cm}$ wide levee on either side. The outer part of the levee profile is determined by the relationship $z=H(L / Y)^{-B}$, where $z$ is the height of the levee, $H$ is the channel depth, $L$ is 


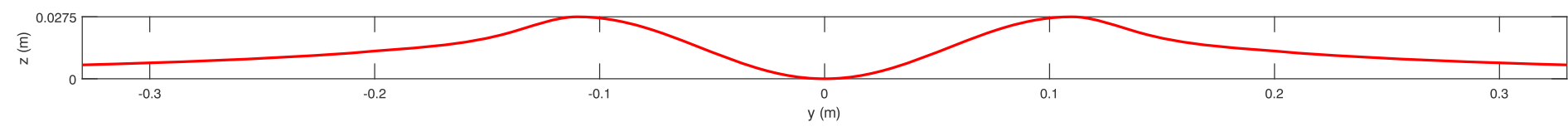

Figure 3. Cross-sectional view of the channel model. The channel measures $0.22 \mathrm{~m}$ wide and $0.0275 \mathrm{~m}$ deep with an aspect ratio of 8 . The profile is that of a sine curve which results in a maximum steepness of $22^{\circ}$. The levee profile was determined using a combination of laboratory data (Straub et al., 2008) and field data (Nakajima \& Kneller, 2013).

the distance from the channel thalweg, $Y$ is half the channel width, and $B=0.5535 S^{0.662}$, where $S$ is the slope. This was found to be give the best fit to channel levees on slopes $>0.6^{\circ}$ by Nakajima and Kneller (2013). Although this relationship works well for the far-field architecture, it fails to capture the morphology near the crest. Therefore, the inner third of the levee profile was determined using data from previous gravity current experiments conducted over an erodible bed (Straub et al., 2008).

The gravity currents were created by preparing a saline solution of $1,025 \mathrm{~kg} / \mathrm{m}^{3}$ density ( $2.5 \%$ excess density). The solution was pumped into the tank and controlled by an electromagnetic flow meter to minimize variation in the input flow rate. Before entering the tank, the fluid passed through a momentum diffuser, manufactured by capping the input pipe and drilling a series of holes in the pipe wall; this pipe was placed within a further inlet pipe which fed an inlet box modeled to fit the channel profile. This ensured that a buoyancydriven flow developed, rather than a dynamically different wall jet driven by inherited momentum and pressure (see supporting information). Fluid was also pumped out from the base of the tank at an equal rate to ensure a constant water depth. Three flow rates were investigated: 0.2 , 1, and $2 \mathrm{~L} / \mathrm{s}$ (Table 2). The $0.2-\mathrm{L} / \mathrm{s}$ flow rate was chosen to give a near bank-full current. The $1-\mathrm{L} / \mathrm{s}$ flow rate was chosen to ensure a large enough quantity of overbank spill to measure with the acoustic Doppler velocimeters (ADVs; see below). The 2-L/s flow rate was chosen as the largest achievable rate for which an appropriate flow duration could be achieved ( $4 \mathrm{~min}$ ) without over-filling the sump. Hereafter these will be referred to respectively as bankfull, equilibrium, and oversize currents (Table 2).

Instantaneous three-component velocities were captured with a profiling Nortek Vectrino II ADV sampling at $100 \mathrm{~Hz}$. Vertical resolution of the data is $1 \mathrm{~mm}$ with each profile extending $30 \mathrm{~mm}$ above the model base. Velocities were recorded both at the channel thalweg and the channel crest.

Ultrasonic Doppler velocity profiling was used at the channel thalweg to capture larger velocity profiles. The ADV velocity profiles were extended with the Ultrasonic Doppler velocity profiling data for the purposes of calculating bulk flow properties.

\subsection{Numerical Model}

Numerical simulations of the laboratory flows and additional flow conditions were performed with a RANS model, solved using the software ANSYS CFX. This is governed by the Reynolds-averaged mass and momentum conservation equations,

$$
\begin{gathered}
\partial \rho+\nabla \cdot(\rho \boldsymbol{u})=0 \\
\frac{\partial \rho \mathrm{u}_{\mathrm{i}}}{\partial \mathrm{t}}+\frac{\partial \rho \mathrm{u}_{\mathrm{i}} \mathrm{u}_{\mathrm{j}}}{\partial \mathrm{x}_{\mathrm{j}}}=-\frac{\partial \mathrm{P}}{\partial \mathrm{x}_{\mathrm{i}}}+\frac{\partial}{\partial \mathrm{x}_{\mathrm{j}}}\left(\mu \frac{\partial \mathrm{u}_{\mathrm{i}}}{\partial \mathrm{x}_{\mathrm{j}}}-\rho \overline{\mathrm{u}_{\mathrm{i}}^{\prime} \mathrm{u}_{\mathrm{j}}^{\prime}}\right)+\rho \mathrm{f}_{\mathrm{i}},
\end{gathered}
$$

where the velocity terms have been separated into Reynolds-averaged components, $u_{i}$, and fluctuating components, $u_{i}^{\prime}$. Reynolds-averaged external forces and pressure are denoted by $f_{i}$ and $P$, respectively.

A shear stress transport turbulence closure has been used to model the Reynolds stresses, $-\rho \overline{u_{i}^{\prime} u_{j}^{\prime}}$. This combines the free-stream capability of the popular $k-\epsilon$ model with the explicit wall resolution of the $k-\omega$ model and was found to perform better when compared with the laboratory data. It is still a two-equation eddy viscosity model, with transport equations for $k$, the turbulent kinetic energy and $\omega$, the turbulence frequency. However, blending functions are utilized in order to exploit the near-wall treatment of the $k-\omega$ model and the free-stream capability of the $k-\epsilon$ model (Menter, 1994). A more detailed description can be found in the supporting information. 


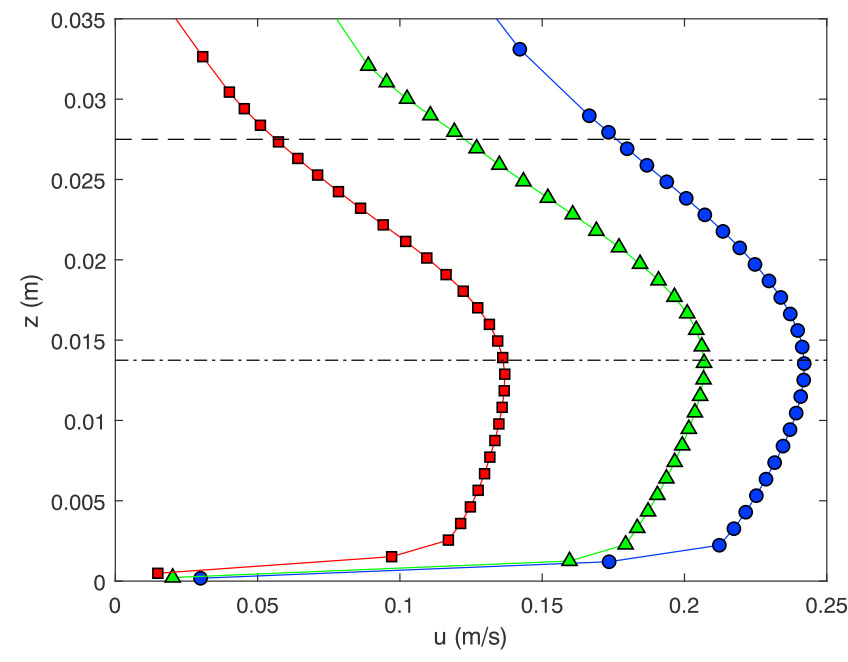

Figure 4. Channel thalweg acoustic Doppler velocimeter velocity profiles measured $1 \mathrm{~m}$ downstream from the main tank inlet, time-averaged over a 3-min period. Red squares $=0.2 \mathrm{~L} / \mathrm{s}$; green triangles $=1 \mathrm{~L} / \mathrm{s}$; blue circles $=2 \mathrm{~L} / \mathrm{s}$. The dashed lines indicate channel depth and half channel depth. The height of the velocity maximum remains almost constant despite changes in flow rate and depth. This is in contrast to confined flows where velocity maximum height scales with flow depth.

To model variations in flow density, a mixture model was employed. This requires the solving of one conservation of mass equation (2) and one conservation of momentum equation (3) for the mixture. In this case, the mixture comprises water and saline with densities $\rho_{w}=1,000 \mathrm{~kg} / \mathrm{m}^{3}$ and $\rho_{s}=1,025 \mathrm{~kg} / \mathrm{m}^{3}$, respectively. The density of the mixture is defined by $\frac{1}{\rho}=$ $\frac{1-\alpha}{\rho_{w}}+\frac{\alpha}{\rho_{s}}$, where $\alpha$ is the saline mass fraction. This variable density is used in all terms of the model, including that of gravity. Additionally, a transport equation is solved for the saline mass fraction,

$$
\frac{\partial \alpha \rho}{\partial t}+\nabla \cdot(\alpha \rho \boldsymbol{u})=-\nabla \cdot\left(\overline{\alpha^{\prime} \rho \boldsymbol{u}^{\prime}}\right)
$$

where the Reynolds flux term is modeled using the eddy diffusion hypothesis as

$$
-\overline{\alpha^{\prime} \rho u_{j}^{\prime}}=\frac{\mu_{t} \partial \alpha}{\sigma_{t} \partial x_{j}}
$$

and $\mu_{t}$, and $\sigma_{t}=1$ are the eddy viscosity and turbulent Schmidt number, respectively. Flow conditions and channel morphology were kept identical to laboratory values. Two larger flows with flow rates of 3 and $4 \mathrm{~L} / \mathrm{s}$, higher than was possible in the laboratory, were also simulated. Moreover, to investigate the role of Reynolds number, a set of flows were simulated in a channel 4 times larger than in the laboratory. Flow rates were scaled upwards by a factor of 16 to ensure the same flow rate per unit area. Table 3 shows the bulk quantities of these flows.

Use and validation of this modeling approach is extensive both in this field (e.g., Imran et al., 2004, 2007; Giorgio Serchi et al., 2011) and related fields (e.g., Doronzo, 2013; Gauer et al., 2005). Additionally, the numerical model has been compared to the experimental data in this study (section 3.1).

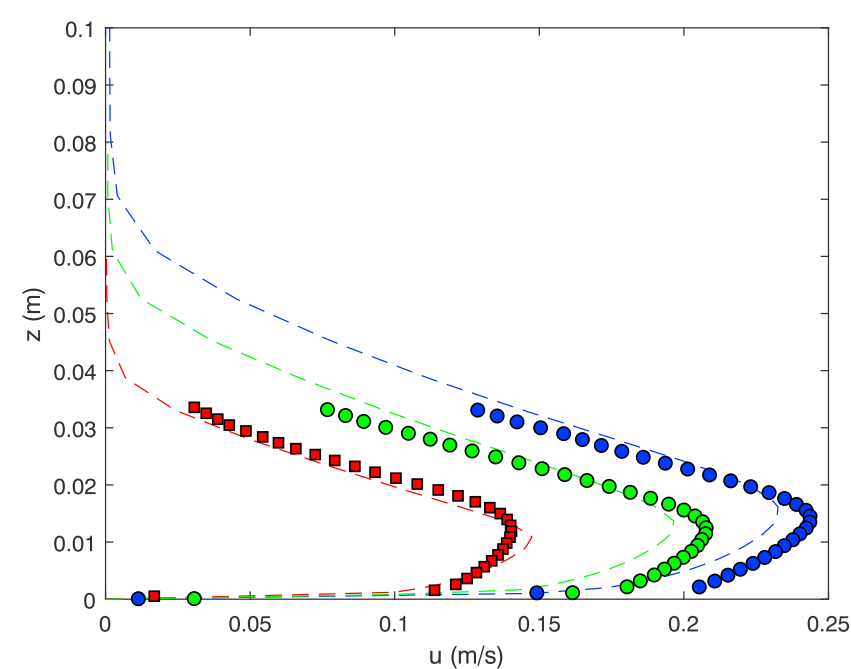

Figure 5. Channel thalweg acoustic Doppler velocimeter (symbols) and numerical (dashed lines) velocity profiles, measured $1 \mathrm{~m}$ downstream from the main tank inlet and time-averaged over a 3-min period. Red $=0.2 \mathrm{~L} / \mathrm{s}$; green $=1 \mathrm{~L} / \mathrm{s} ;$ blue $=2 \mathrm{~L} / \mathrm{s}$. Data are not normalized to explicitly show similarities and differences.

\section{Results}

\subsection{Velocity and Density Structure}

The velocity profiles of the three laboratory flows are shown in Figure 4. These were captured with an ADV $1 \mathrm{~m}$ downstream of the main tank inlet to allow the flows to develop. As has been observed in many previous studies (e.g., Ellison \& Turner, 1959; Garcia \& Parker, 1993; Islam \& Imran, 2010) all profiles exhibit a lower shear layer caused by basal drag and an upper shear layer caused by drag and subsequent mixing with the ambient fluid. These are separated by a velocity maximum. Here the height of the velocity maximum remains almost constant for all flows at a height equal to half the channel depth. This is despite the changes in flow height, discharge, and Richardson number, suggesting that channel depth is a key control on partially confined flow development.

The numerical simulations predict velocity profiles that compare well with the laboratory data (Figure 5) and model performance is comparable to previous gravity current studies (e.g., Giorgio Serchi et al., 2011; Huang et al., 2005). Except for the bank-full flow, the constant velocity maximum height is replicated (Figure 6) and the simulations show it remains constant at flow magnitudes larger than were possible in the laboratory. The upper shear layers are captured well, although the numerical simulations predict slightly different magnitudes for the maximum velocity and lower shear layer. In accordance with previous laboratory (e.g., Islam \& Imran, 2010; Sequeiros et al., 2010) and numerical studies (e.g., Imran 

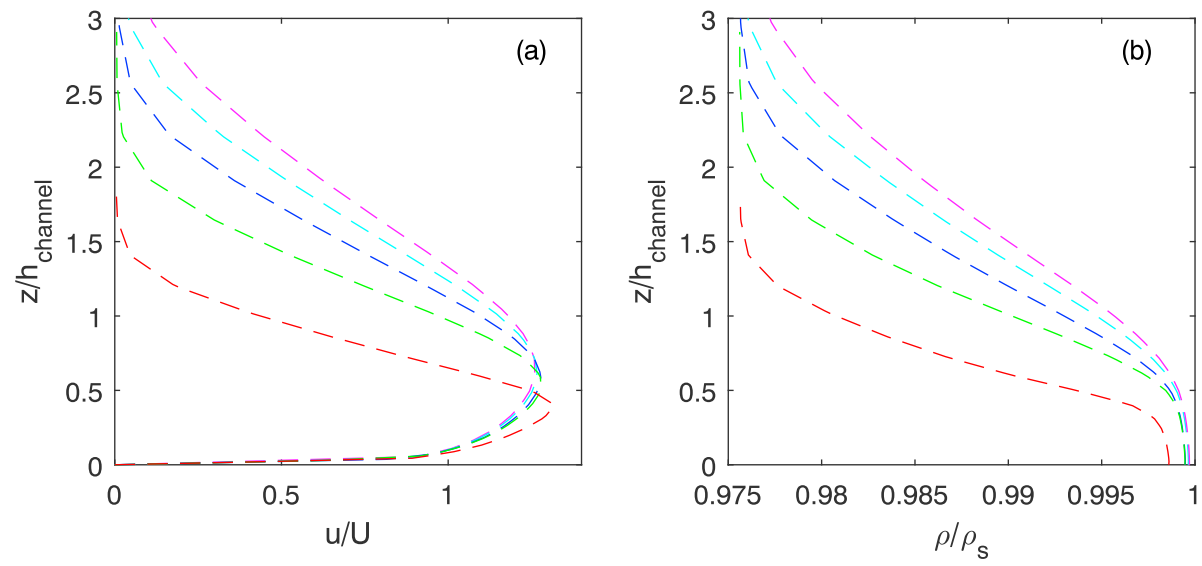

Figure 6. Channel thalweg numerical velocity (a) and density (b) profiles, normalized with depth-averaged velocity/saline density and channel depth, measured $1 \mathrm{~m}$ downstream from the main tank inlet and time-averaged over a 3-min period. Red $=0.2 \mathrm{~L} / \mathrm{s}$; green $=1 \mathrm{~L} / \mathrm{s}$; blue $=2 \mathrm{~L} / \mathrm{s} ;$ cyan $=3 \mathrm{~L} / \mathrm{s}$; magenta $=4 \mathrm{~L} / \mathrm{s}$. Numerical simulations show a constant velocity maximum height for larger flow rates and heights than could be achieved in the laboratory. With the exception of the bank-full flow (red trace), both velocity and density profiles collapse well in the lower shear layer where large levels of stratification are present.

et al., 2004, 2007; Giorgio Serchi et al., 2011; Kneller et al., 2016), the simulations provide density data that show a stratified region below the velocity maximum with an increasingly mixed region above. The collapse of the simulated profiles in the lower shear layer (Figure 6) shows the bank-full flow to be characteristically different to the larger, overspilling flows, suggesting that overspill plays an important role in the development of flow structure.

\subsection{High Reynolds Number Simulations}

In order to investigate the effect of Reynolds number, flows were simulated in a channel scaled 4 times larger than the laboratory geometry. To compare to the laboratory scale flows, flow rates were scaled upwards by a factor of 16 to keep the same flow rates per unit area. The resultant flows had Reynolds numbers between 20,900 and 73,300 (Table 3). The thalweg velocity and density profiles are shown in Figure 7. Similarly to the laboratory scale flows, the height of the velocity maximum of these larger remains fixed at around half the channel depth. The smallest, bank-full flow shows distinctly different characteristics with a relatively faster, more mixed core.
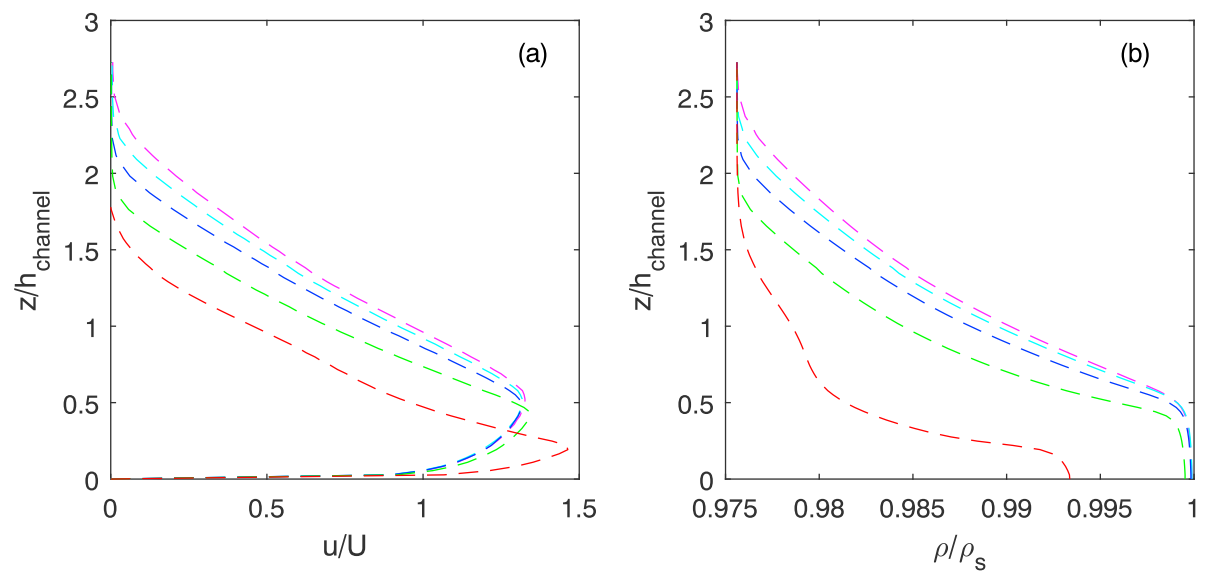

Figure 7. Channel thalweg numerical velocity (a) and density (b) profiles for the higher Reynolds number flows traversing the scaled-up channel. Profiles are normalized with depth-averaged velocity/saline density and channel depth, measured $4 \mathrm{~m}$ downstream from the main tank inlet. Red $=3.2 \mathrm{~L} / \mathrm{s}$; green $=16 \mathrm{~L} / \mathrm{s}$; blue $=32 \mathrm{~L} / \mathrm{s}$; cyan $=48 \mathrm{~L} / \mathrm{s}$; magenta $=64 \mathrm{~L} / \mathrm{s}$. 

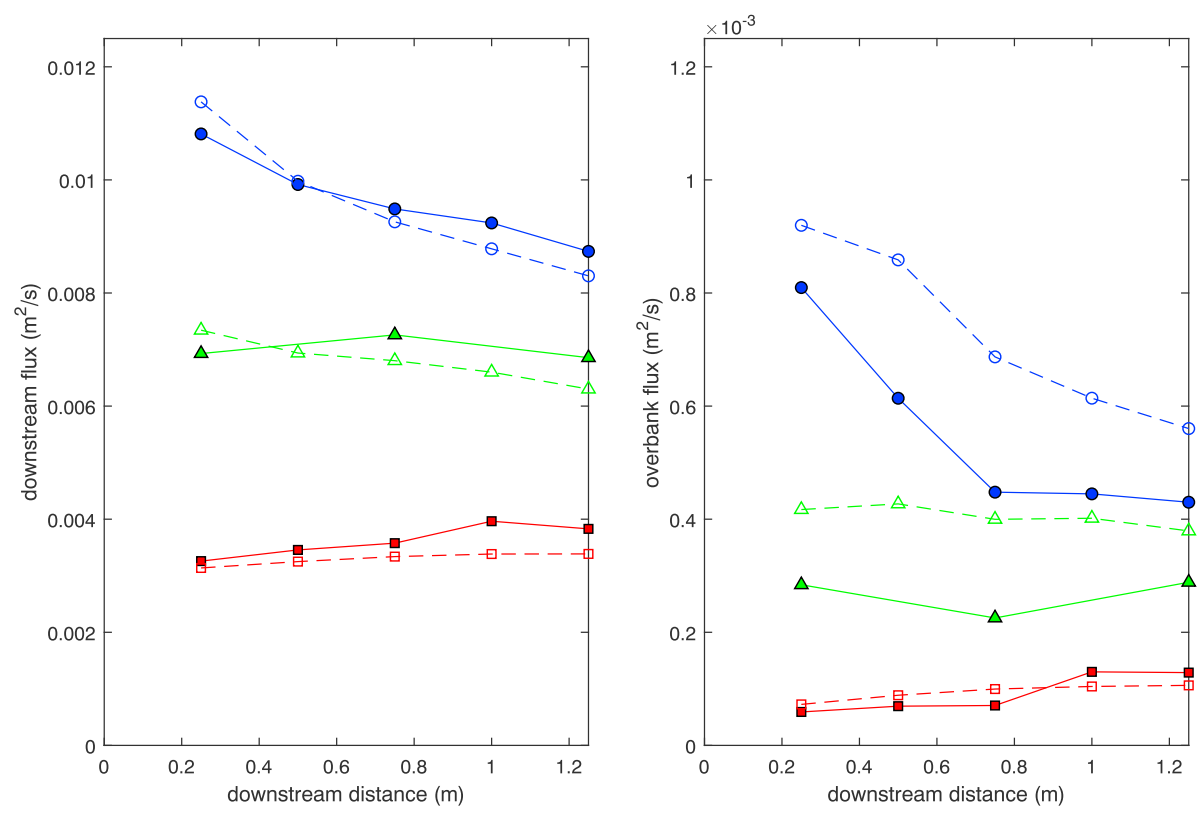

Figure 8. Downstream evolution of streamwise and overbank discharges from laboratory data (solid) and numerical simulations (dashed). Red $=0.2 \mathrm{~L} / \mathrm{s}$; green $=1 \mathrm{~L} / \mathrm{s}$; blue $=2 \mathrm{~L} / \mathrm{s}$. The simulations predict the spatial evolution well, although they overestimate the magnitude of overspill for the two larger flows. Flow tuning is evident in the different ways each flow evolves. Both the streamwise and overbank discharge of the $0.2-\mathrm{L} / \mathrm{s}$ flow increase downstream as ambient fluid is entrained and the flow inflates. The discharges of the 1-L/s flow remain relatively constant indicating a close-toequilibrium balance between overbank losses and ambient entrainment. The discharge of the 2-L/s flow changes rapidly with large initial overbank losses. The streamwise discharge continues to reduce downstream, despite ambient entrainment.

\subsection{Flow Evolution and Overspill}

Total streamwise and overbank discharges are shown in Figure 8 using both the laboratory and numerical data. The simulations predict the downstream discharge well, showing close agreement with both the magnitudes and the spatial evolution. The downstream evolution of the overbank losses is also predicted well, although magnitudes for the two larger flows were over-predicted by $13-73 \%$.

The three currents clearly interact with the channel in different ways. The bank-full current is dominated by ambient entrainment and as a result the streamwise discharge increases downstream. Overbank losses subsequently also increase as the current inflates and overspills the confinement of the channel. Both the streamwise discharge and overbank losses of the equilibrium current remain fairly constant, suggesting a balance between entrainment and overspill. The oversize current exhibits large initial overbank losses which result in a reduction in streamwise discharge. Overspill rates reduce rapidly downstream however as the current size reduces. These are examples of the two main ways-inflation versus deflation-in which a current can evolve and be "tuned" to equilibrium by a channel.

\subsection{Entrainment}

The entrainment of a flow can be found by a depth integration of the incompressibility equation,

$$
\frac{\partial}{\partial \mathrm{x}} \int_{0}^{\infty} \mathrm{udz}+\frac{\partial}{\partial \mathrm{y}} \int_{0}^{\infty} \mathrm{vdz}+\mathrm{w}_{\infty}=0
$$

where $w_{\infty}=\partial h / \partial t-w_{e}$ is a product of the shallow-water approximation (Parker et al., 1986). Assuming a temporally stable flow, and using definitions in Table 1 , this becomes

$$
e_{W}|\mathrm{U}|=\frac{\partial \mathrm{Uh}}{\partial \mathrm{x}}+\frac{\partial \mathrm{Vh}}{\partial \mathrm{y}}
$$


Table 1

Variable and Notation Definitions

\begin{tabular}{|c|c|}
\hline Variable & Expression \\
\hline Flow depth & $h=\frac{\left(\int_{0}^{\infty}|u| \mathrm{d} z\right)^{2}}{\int_{0}^{\infty}|u|^{2} \mathrm{~d} z}$, where $|u|=\sqrt{u^{2}+v^{2}}$ \\
\hline Depth-averaged velocity & $U=\frac{\int_{0}^{\infty} u \mathrm{~d} z}{h}, V=\frac{\int_{0}^{\infty} v \mathrm{~d} z}{h},|U|=\frac{\int_{0}^{\infty}|u| \mathrm{d} z}{h}$ \\
\hline Reynolds number & $\operatorname{Re}=\frac{|U| h}{v}$ \\
\hline Froude number & $F r=\frac{|U|}{\sqrt{g^{\prime} h}}$ \\
\hline Richardson number & $R i=\frac{g^{\prime} h}{|U|^{2}}$ \\
\hline Reduced gravity & $g^{\prime}=g \frac{\bar{\rho}-\rho_{\text {ambient }}}{\rho_{\text {ambient }}}$, where $\bar{\rho}=\frac{\int_{0}^{\infty} \rho \mathrm{d} z}{h}$ \\
\hline Gradient Richardson number & $R i_{g}=\frac{-\frac{g \rho \rho}{\partial j}}{\rho\left(\frac{\partial u \mid u}{\partial z}\right)^{2}}$ \\
\hline
\end{tabular}

where the entrainment velocity, $w_{e}=e_{W}|U|$, has been defined as a product of the entrainment coefficient, $e_{W}$, and the depth-averaged velocity magnitude of the flow. The entrainment coefficient describes the ability of a flow to entrain ambient fluid. For fully confined flows with no crossstream variation, (7) becomes

$$
\mathrm{e}_{\mathrm{W}} \mathrm{U}=\frac{\partial \mathrm{Uh}}{\partial \mathrm{x}}
$$

which is the standard form used for confined laboratory flows (Parker et al., 1987). For partially confined flows in a straight channel, when integrated across the channel from thalweg to crest, (5) becomes

$$
\widehat{e}_{W} \widehat{\mid U} \mid Y=\frac{\partial \widehat{U} A}{\partial x}+V(Y) h(Y)
$$

where the cross-sectional area of the current is defined as $A=\int_{0}^{Y} h \mathrm{~d} y$, channel average velocities as $\widehat{\mid U} \mid=\left(\int_{0}^{Y} \int_{0}^{h}|u| \mathrm{d} z \mathrm{~d} y\right) / A$, the channel average entrainment coefficient as $\widehat{e}_{W}=\left(\int_{0}^{Y} e_{W}|U| \mathrm{d} y\right) / \widehat{U} \mid Y$, and $Y$ is half the channel width. The values of $e_{W}$ presented here are all calculated using (9). If (8) is used for an overspilling, partially confined flow, negative values will be observed if the current is deflating. Such a current is still clearly entraining ambient fluid and shows how overspill must be taken into account when analyzing the entrainment characteristics of such flows. A channel-average Richardson number, defined as the mean of the thalweg and crest Richardson number, is also used in order to account for cross-stream variations.

Both the laboratory and numerical data output entrainment coefficients of the same order of magnitude (Figure 9), with the range of simulated values overlapping with the laboratory counterparts. However, the simulated values, based on the numerical velocity and density data, largely predict higher values. This is attributed mostly to the overprediction over overbank losses (Figure 8). The difference between simulated and laboratory values is largest for the $1 \mathrm{~L} / \mathrm{s}$ flow which is attributed to the lower longitudinal resolution in the laboratory data for this flow. A clear difference can be seen between the bank-full and the larger, overspilling flows. The dependence of $e_{W}$ on Richardson number for fully confined flows, described by Parker et al. (1987) using (1), still appears to hold for the partially confined setting. Figure 10 shows how the data presented here fall within the scatter of the previous laboratory data. However, there is also an apparent upper bound on $e_{W}$ for these partially confined flows. Neither an increase in flow magnitude, nor a reduction in Richardson number, results in a change in $e_{W}$ (Figures 9 and 10), perhaps suggesting a limit imposed on the entrainment ability of a current by the channel.

Further evidence for the "tuning" effect of the channel described above is displayed in Figure 11. The downstream evolution of the Richardson number shows how each flow approaches an equilibrium. This is particularly evident in the thalweg. Cross-sectional contours of gradient Richardson number in Figure 12, produced using numerical simulation data, show how the stability of the stratification varies throughout each of the flows. The vertical structure is typical of a gravity current (Kneller et al., 2016), with values approaching infinity around the velocity maximum due to the reversal of the velocity gradient while a less stable layer above this that helps to drive entrainment. Here localized low gradient Richardson regions are seen over the levee crests.

A reduction in bulk Richardson number is also seen over the levee crests for all flows. Similar cross-stream variations and magnitudes are found for the gradient Richardson number when depth-averaged over the upper shear layer. The depth-averaging region was defined to be between 0.5 and 2.5 standard deviations above the velocity maximum, found by approximating the upper velocity profile with a Gaussian distribution. This region was chosen to include the entire upper shear layer which is 
Table 3

Bulk Flow Properties of the Numerically Simulated Flows Calculated From Channel Thalweg Data, $1 \mathrm{~m}$ Downstream From the Main Tank Inlet

\begin{tabular}{lcccccccccc}
\hline Input flow rate $(\mathrm{L} / \mathrm{s})$ & 0.2 & 1 & 2 & 3 & 4 & 3.2 & 16 & 32 & 48 \\
\hline$h(\mathrm{~cm})$ & 3.05 & 4.36 & 5.01 & 5.43 & 5.69 & 11.7 & 15.1 & 17.2 & 18.5 \\
$U(\mathrm{~m} / \mathrm{s})$ & 0.111 & 0.151 & 0.175 & 0.194 & 0.212 & 0.179 & 0.294 & 0.325 & 0.353 & 0.377 \\
$R e$ & 3,390 & 6,580 & 8,770 & 10,500 & 12,100 & 20,900 & 44,300 & 55,900 & 65,100 & 73,300 \\
$F r$ & 1.64 & 1.84 & 1.96 & 2.03 & 2.15 & 1.77 & 1.89 & 1.89 & 1.97 & 2.06 \\
$R i$ & 0.372 & 0.295 & 0.260 & 0.243 & 0.216 & 0.321 & 0.251 & 0.281 & 0.257 & 0.235 \\
\hline
\end{tabular}

Note. Flows in the second to sixth columns traverse the laboratory scale channel, with the flows in the seventh to eleventh columns traversing a channel scaled 4 times larger.

responsible for ambient entrainment while excluding the very high magnitudes found around the velocity maximum. This region also spans above the flow height determined by the Ellison and Turner (1959) definition (Table 1) which is used in the calculation of bulk quantities.

\section{Discussion}

\subsection{Channel Forcing}

The occurrence of overspill and associated inherent cross-stream variation mean the dynamics of a partially confined flow are fundamentally different to those of a fully confined flow. For a fully confined flow, the velocity maximum height, $h_{\max }$, is determined solely by the balance between basal and ambient drag (Middleton, 1993); $h_{\max }$ scales with height, with values observed between $h_{\max } / h=0.1$ (Buckee et al., 2001) and $h_{\max } / h=0.3$ (Kneller et al., 1999). Variations are to be expected with differences in basal materials, laboratory conditions and the difficulty in defining a current's height. A dependence of $h_{\max }$ on both the flow's Richardson number (Sequeiros et al., 2010) and Reynolds number (Stagnaro \& Pittaluga, 2014) has also been observed. For the partially confined flows analyzed here, $h_{\max }$ remains nearly constant for all the laboratory-scale flows at a height equal to half the channel depth, regardless of flow height or Richardson number. This could suggest an increase in the ratio of ambient to basal drag for larger flows, perhaps due to the increase in overspill and the surface area of the ambient interface. For the upscaled flows, described in section 3.2, the smaller flows have a relatively lower position of $h_{\text {max }}$. This can be explained by the basal drag remaining constant but ambient drag increasing with Reynolds number. However, half

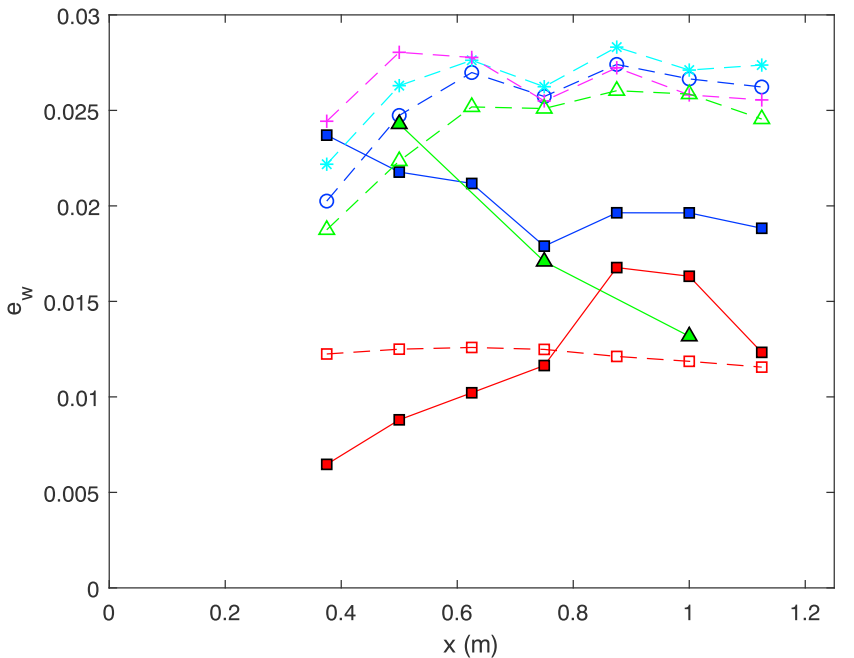

Figure 9. Downstream evolution of entrainment coefficient. Laboratory $=$ solid; numerical $=$ dashed. Red $=0.2 \mathrm{~L} / \mathrm{s}$; green $=1 \mathrm{~L} / \mathrm{s}$; blue $=2 \mathrm{~L} / \mathrm{s} ;$ cyan $=3 \mathrm{~L} / \mathrm{s} ;$ magenta $=4 \mathrm{~L} / \mathrm{s}$. The magnitudes of the entrainment coefficient show overlap between the numerical and experimental data, although the simulations largely predict slightly higher values. the channel depth remains as an upper limit on $h_{\max }$ for the larger flows indicating that, even at large Reynolds numbers, channel depth remains a first-order control on flow structure.

It would appear the channel has the ability to maintain a high-velocity "core" (illustrated in Figure 13). A value of $h_{\max }$ less than the channel depth allows the current to maintain a highly stratified lower region confined by the base of the channel. This region provides a gravitational driving force that is sustained along the length of the channel and enables the possibility of a stable downstream flow evolution pattern. The forcing on the current exerted by the channel is therefore further confirmed as a key control on the flow dynamics and can be recognized as an important mechanism in sustaining current run-out.

It is unclear at what point $h_{\text {max }}$ could exceed the channel depth, although this would make a rapid dissipation of the current likely, with the lower region no longer fully restricted and nothing to prevent lateral spreading. In a laboratory study with varying levels of flow confinement, Mohrig and Buttles (2007) defined a threshold of $h / H>5$, where $H$ is the channel depth to differentiate confined versus effectively unconfined flow. It was proposed that at this threshold the high-velocity core exceeds the confines of the channel, resulting in an unconfined flow, although there was no vertical resolution in the velocity data which were acquired from 

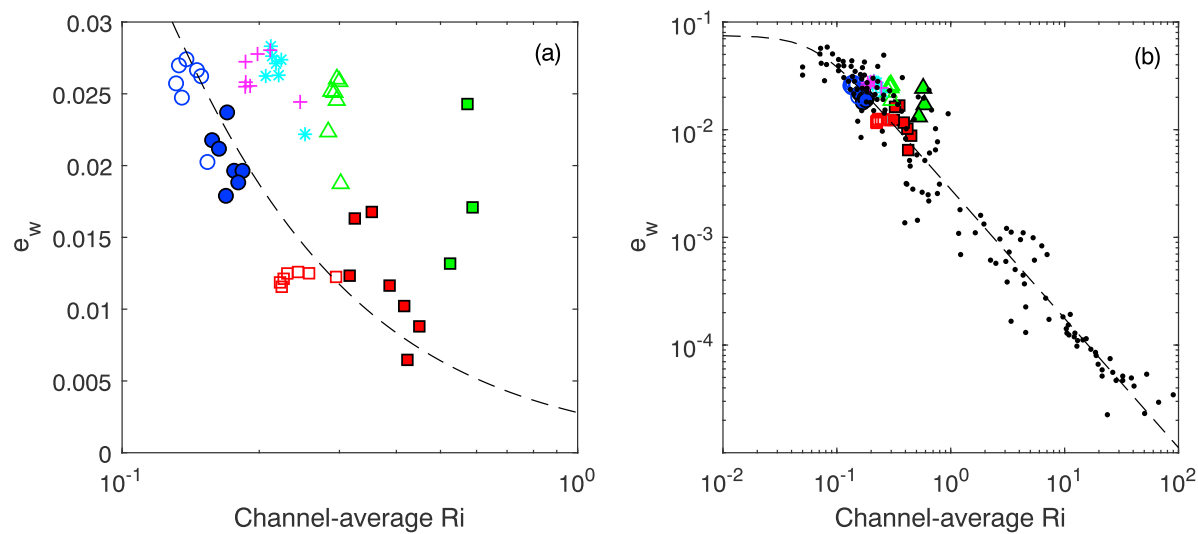

Figure 10. Entrainment coefficient is dependent on the (channel average) Richardson number. Laboratory = filled; numerical $=$ hollow. Red $=0.2 \mathrm{~L} / \mathrm{s} ;$ green $=1 \mathrm{~L} / \mathrm{s} ;$ blue $=2 \mathrm{~L} / \mathrm{s} ;$ cyan $=3 \mathrm{~L} / \mathrm{s} ;$ magenta $=4 \mathrm{~L} / \mathrm{s}$. Data shown on a linear axis (a) and a logarithmic axis (b). The dashed line indicates the Parker et al. (1987) relationship (1). Previous experimental data from confined flows, collated by Parker et al., are shown in black in (b) (Ashida \& Egashira, 1975; Ellison \& Turner, 1959; Lofquist, 1960). The standard deviation of the entrainment coefficient from the defined relationship is 0.041 for the previous confined data and 0.015 for the data presented here.

overhead cameras. The laboratory and simulated flows described here have values in $h / H$ ranging from 1.15 to 3 . While none of these flows approach the $h / H>5$ threshold, the constant height of the velocity maximum suggests any transition would not be gradual.

\subsection{Numerical Model Performance}

A numerical RANS model with a shear stress transport turbulence closure has been used to simulate flows with magnitudes too large to produce in this laboratory setup and investigate the role of higher Reynolds numbers. Performance, in terms of agreement with laboratory velocity data, is comparable to those of similar models (e.g., Giorgio Serchi et al., 2011; Imran et al., 2007). Crucially, the numerical model helps to show how the constraint of the half channel depth on the velocity maximum height is not an artifact of the lower Reynolds numbers found in the laboratory. An increase in Reynolds number (section 3.2), and the resultant increase in ambient drag, has limited impact on this upper constraint. The comparison between the laboratory and numerical velocity profiles (Figure 5) shows reasonably good agreement, particularly with the velocity gradients in the shear layers. However, there are still clear differences between the simulations and the experiments. While the velocity maximum heights are predicted well for the 1 and $2 \mathrm{~L} / \mathrm{s}$ flows, the height is
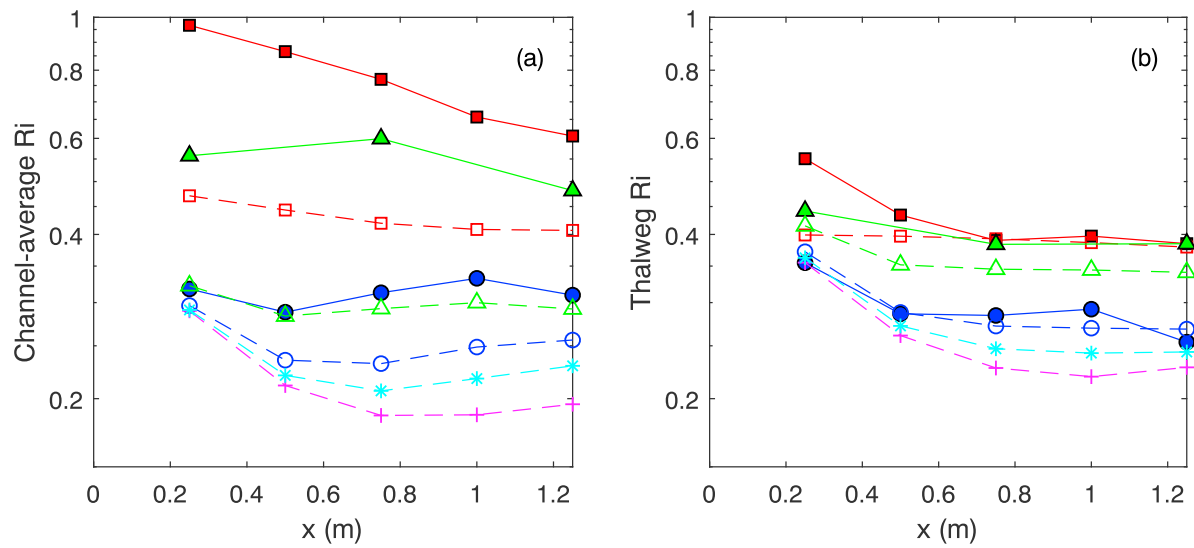

Figure 11. Downstream development of channel-average (a) and thalweg (b) Richardson number. Laboratory = solid; $\mathrm{CFD}=$ dashed. Red $=0.2 \mathrm{~L} / \mathrm{s}$; green $=1 \mathrm{~L} / \mathrm{s} ;$ blue $=2 \mathrm{~L} / \mathrm{s} ;$ cyan $=3 \mathrm{~L} / \mathrm{s} ;$ magenta $4 \mathrm{~L} / \mathrm{s}$. Numerical simulation density data are used in the calculation of the laboratory values in the absence of laboratory density data. There is an adjustment period before each flow approaches an equilibrium Richardson number, the distance of which is dependent on flow magnitude. 

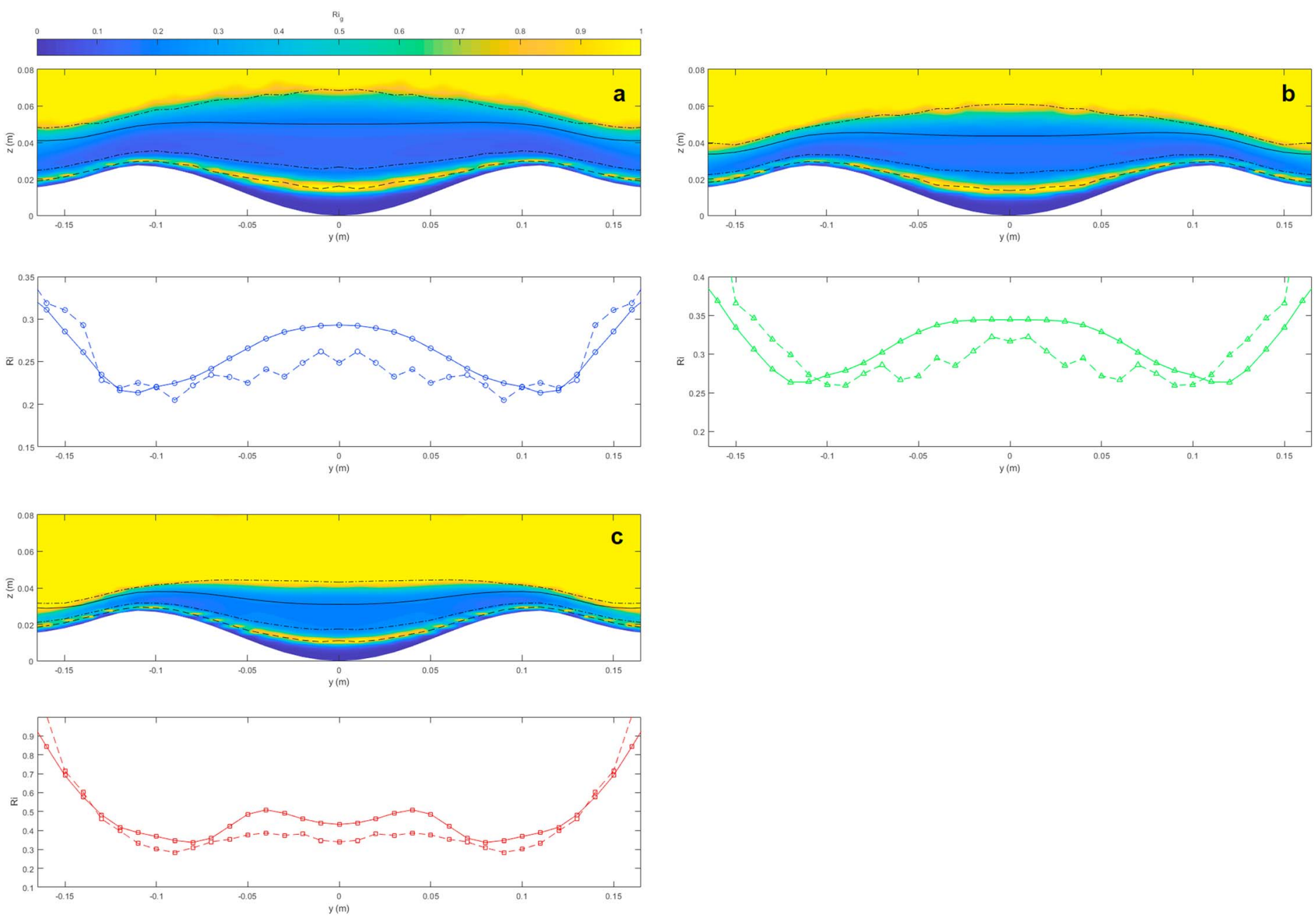

Figure 12. (a) $2 \mathrm{~L} / \mathrm{s}$; (b) $1 \mathrm{~L} / \mathrm{s}$; (c) $0.2 \mathrm{~L} / \mathrm{s}$. Gradient Richardson contours for each flow rate exhibit regions of decreased magnitudes above the levee crests and indication of decreased stability and increased mixing. Both the cross-stream variations and magnitudes of the bulk Richardson number (solid line) are comparable with the depth-averaged gradient Richardson number (dashed line). The bulk Richardson number would appear to be a good proxy for the gradient Richardson number in the upper shear layer and a good indication of mixing levels. The depth average was calculated between 0.5 and 2.5 standard deviations (dash-dotted lines) above the velocity maximum (dashed line). The flow height is also shown with a solid line.

underpredicted for the smallest $0.2 \mathrm{~L} / \mathrm{s}$ flow. There are also discrepancies of up to $7 \%$ in the magnitudes of the velocity maxima. The modeling of the stratification and subsequent levels of overbank losses could be one source of these errors, with Figure 8 showing significant overprediction of overbank loss. Furthermore, the time-averaging introduced in RANS modeling could not completely capture the effect of large-scale, transient flow features such as the mixing introduced by Kelvin-Helmholtz instabilities at the ambient interface. Finally, the use of numerical density data in the calculation of laboratory Froude number and entrainment coefficient values means that discrepancies in these areas are introduced solely from the observed differences in velocity data.

\subsection{Flow Tuning}

A channel is clearly capable of tuning oversize flows via overspill, with deflation and flow stripping occurring here for flows with $h / H>1$.9. Mohrig and Buttles (2007) also observed this tuning effect, reporting flows with $h / H>1.3$ undergoing deflation until a constant flow height was reached. At the laboratory scale at least, such oversize flows appear to be unable to propagate in a partially confined setting. While it is therefore unlikely the $h / H>5$ threshold would be breached via gradual flow evolution, external factors could trigger this scenario. A current emerging from a canyon system could be disproportionally deep before being 

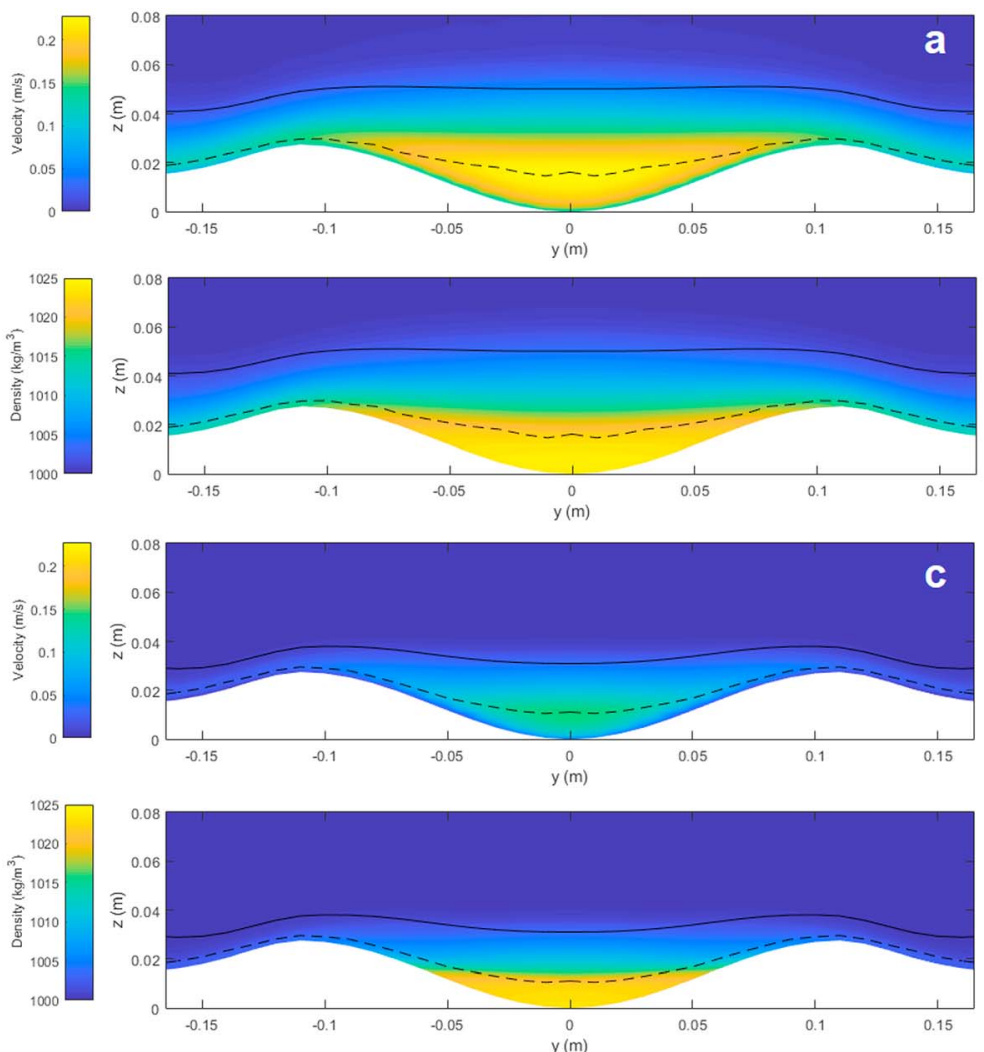
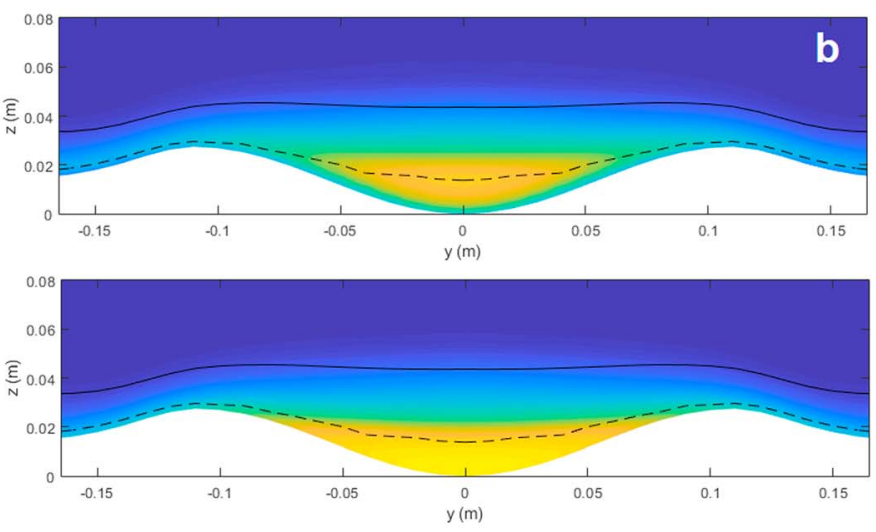

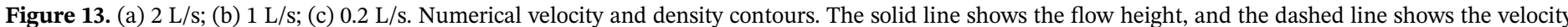

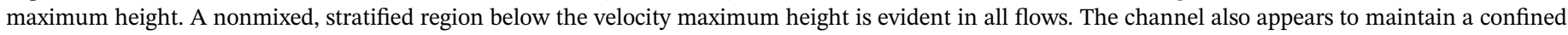
"high-velocity core."

stripped or thinned by the channel, analogous to the oversize current described here that experienced significant overspill proximally (Figure 8). A break in slope, as often seen at a channel-lobe transition zone (Dorrell et al., 2016; Wynn et al., 2002), could also cause a sudden thickening of the flow and a subsequent avulsion or transition to unconfinement. Additionally, increasing channel instability, caused by continual deposition, could lead to a channel being unable to provide the necessary degree of confinement to contain the high-velocity core (Dorrell et al., 2015). Here we are considering the dynamics of straight channel confinement; channel sinuosity leads to flow elevation at bend apexes (Cossu \& Wells, 2010; Dorrell et al., 2013; Keevil et al., 2006), providing an additional mechanism for flow avulsion.

While the size of the flow can be tuned via overspill, ambient entrainment can also lead to the inflation of an undersize flow. This mechanism allows the achievement of an equilibrium whereby a current's overbank losses are balanced with ambient entrainment. In contrast, entrainment is the sole mechanism for fully confined flow evolution, resulting in continued inflation (Symons et al., 2017). Here a quasi-equilibrium current, characterized by $h / H=1.75$, can be identified in the $1 \mathrm{~L} / \mathrm{s}$ case. Both streamwise and overbank discharges remain relatively constant along the length of the channel (Figure 8). Further evidence of tuning can be seen in Figure 11. Each flow must propagate for a characteristic length before attaining a constant Richardson number, with the magnitude of this length correlated with the size of the flow. It is unlikely, however, that for a given channel geometry, there exists a unique equilibrium flow condition that all currents evolve towards regardless of input. Rather, a partially confining channel allows a range of currents to develop a balance between ambient entrainment and overbank losses which allows stable downstream evolution. These mechanisms are illustrated in Figure 14.

If a channel has the capability to modify flows along its length, an impact in the overbank deposit record would be expected. Differing levels of overspill near the channel inlet followed by an approach to an equilibrium value would suggest a transformation from heterogeneous overbank deposits proximally to 


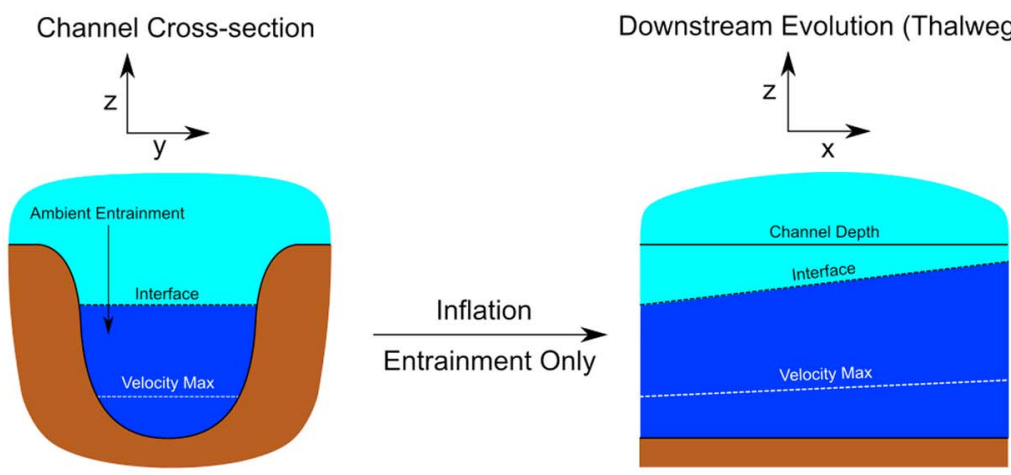

Fully-Confined
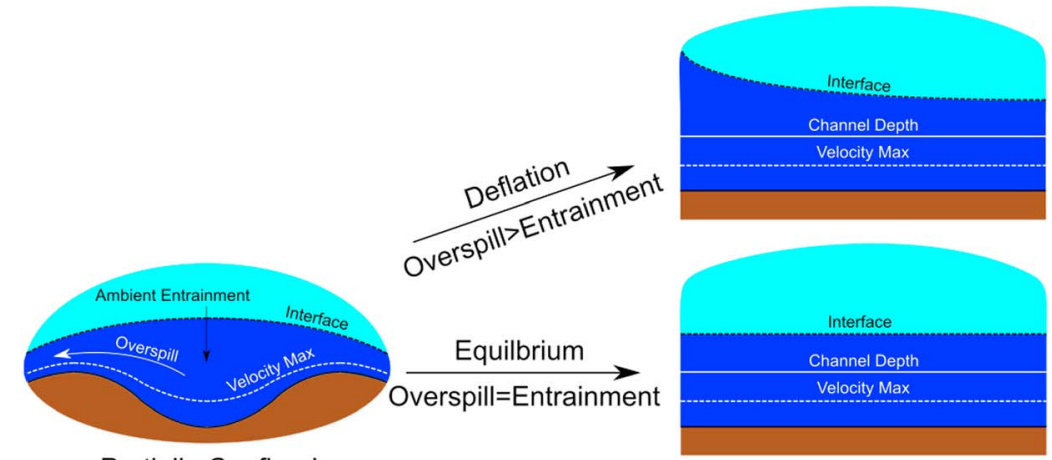

Partially-Confined
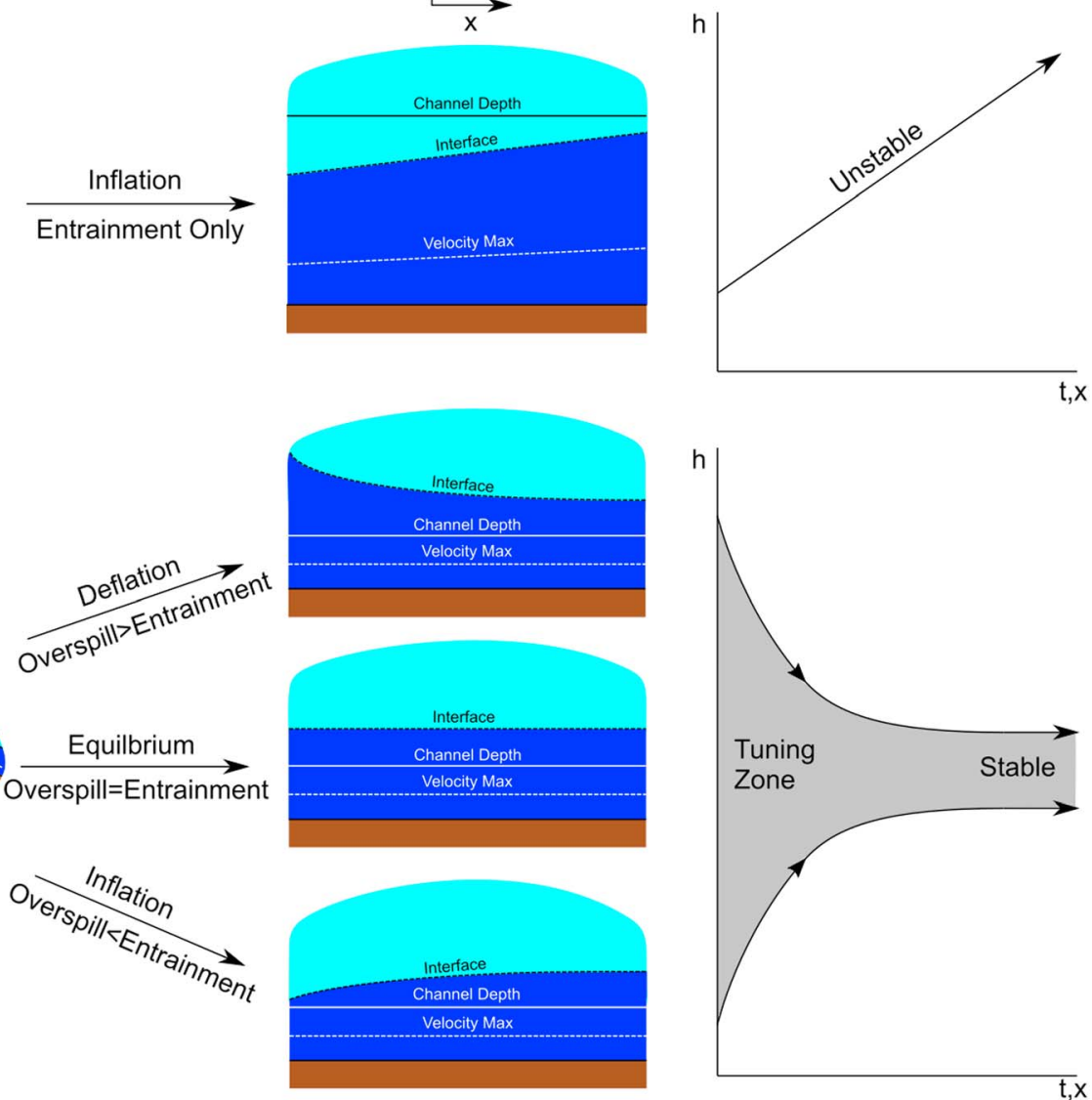

Figure 14. Downstream evolution patterns of fully and partially confined flows. Entraining fully confined flows can only inflate in an unstable evolution pattern. Partially confined flows can either inflate or deflate to approach a stable equilibrium where overbank losses are balanced by ambient entrainment.

homogenous deposits distally. This is, however, based on the assumption that all overbank flow is of a similar depositional character. Larger overbank flows may bypass the channel-proximal levee, significantly complicating the depositional record in these locations.

\subsection{Entrainment and Cross-Stream Variation}

It can be seen from (9) that for a partially confined flow the overspill term, $V h$, has a significant impact on the entrainment. This is evident in the markedly lower entrainment coefficient values for the bank-full flow (Figure 9). It is also the primary reason for the difference in simulated and laboratory values (Figure 8 shows how the numerical model over-predicts overspill levels for the larger flows). It is therefore slightly surprising that, for a given Richardson number, these partially confined flows exhibit similar entrainment rates to fully confined flows (Figure 10), despite the differences in flow dynamics described above, such as the occurrence of overspill. It should be noted that the calculation of the Richardson numbers for the laboratory flows is dependent on the numerical density data. Given the relatively low spread of this and previous data, however (see Figure 10), it is unlikely any discrepancies would significantly affect the Richardson number calculations or any conclusions drawn.

As is the case with the velocity maximum height, there does appear to be an upper limit on flow entrainment efficiency. Despite an increase in input flow rate and a reduction in thalweg Richardson number (Table 3), the larger 3 and $4 \mathrm{~L} / \mathrm{s}$ laboratory scale flows do not exhibit higher values of entrainment coefficient. This appears to be driven by a lower Richardson number at levee crests resulting in a lower channel average Richardson number and the corresponding associated average entrainment characteristics. Again, the 
constraints of the channel morphology and the increasing levels of overspill appear to be a key control on flow dynamics.

For all the flows considered it is important to take into account cross-stream variations, as these can be significant, affecting not only calculated entrainment levels but also definitions of Richardson number. The bulk Richardson number is often used as an approximation for the gradient Richardson number (see definitions in Table 1), which can be used to identify regions of increased mixing due to buoyant instability. For partially confined flows, these regions occur above both levee crests (Figure 12) highlighting how mixing processes at channel boundaries are key to the entrainment process. Using 2D direct numerical simulation of the Navier-Stokes equations, Kneller et al. (2016) found that the bulk Richardson number was not a good measure of the gradient Richardson number, which served as a good indicator to a flow's entrainment behavior. Here though, the bulk Richardson number, for all flows, appears to be a good proxy for the gradient Richardson number in the upper shear layer (Figure 12). This is the region responsible for ambient entrainment and thus of most interest when examining mixing rates. Both the magnitudes and the cross-stream variations are captured well in the numerical modeling reported here. It is possible that the $2 \mathrm{D}$ nature of the simulations reported by Kneller et al. (2016) may have resulted in the artificial dampening of some of the flow's mixing mechanisms.

\section{Conclusions}

Both laboratory experiments and numerical simulations show that for a partially confined gravity current the geometry of the containing channel is a first-order control on the flow dynamics. Here at the laboratory scale, the height of the velocity maximum for a range of flows was not affected by changes in multiple factors including flow height and Richardson number. The velocity maximum remained fixed at a height equal to half the channel depth, which resulted in the development of a high-velocity core and highly stratified lower shear layer, both confined within the channel. Numerical simulations at larger Reynolds numbers confirm the half channel depth upper limit on the velocity maximum height. The channel form plays a key factor in controlling the downstream evolution of the current. The joint mechanisms of overspill and ambient entrainment allow partially confined flows to either deflate or inflate towards a quasi-equilibrium state. There are significant cross-stream variations in the Richardson and gradient Richardson numbers of partially confined flow. Low Richardson number regions observed over the levee crests indicate increased levels of mixing and highlight the importance of overspill in the entrainment process. Despite this, the entrainment coefficients for a given Richardson number are similar to those of fully confined flows in previous studies.

\footnotetext{
Acknowledgments

This work is supported by the Engineering and Physical Sciences Research Council (EPSRC) Centre for Doctoral Training in Fluid Dynamics grant EP/L01615X/1 and the TRG consortium (Anadarko, BG-Group, BHP-Billiton, BP, Conoco Phillips, Equinor, Marathon Oil, Maersk Oil, Nexen, Tullow, and Woodside). We thank Kyle Straub for providing laboratory data used in the channel design process and Helena Brown, Gareth Keevil, and Robert Thomas for their invaluable help in the Sorby Laboratory. We also thank two anonymous reviewers whose valuable input led to an improvement in this work; Laboratory ADV data and ANSYS input and output files can be found at the website (https://doi.org/ 10.5518/412).
}

\section{References}

Abd El-Gawad, S., Cantelli, A., Pirmez, C., Minisini, D., Sylvester, Z., \& Imran, J. (2012). Three-dimensional numerical simulation of turbidity currents in a submarine channel on the seafloor of the Niger Delta slope. Journal of Geophysical Research, 117, C05026. https:// doi.org/10.1029/2011JC007538

Ashida, K., \& Egashira, S. (1975). Basic study on turbidity currents. Proceedings. Japan Society of Civil Engineers, $237,37-50$.

Azpiroz-Zabala, M., Cartigny, M. J., Sumner, E. J., Clare, M. A., Talling, P. J., Parsons, D. R., \& Cooper, C. (2017). A general model for the helical structure of geophysical flows in channel bends. Geophysical Research Letters, 44, 11,932-11,941. https://doi.org/10.1002/ 2017GL075721

Bonnecaze, R. T., Huppert, H. E., \& Lister, J. R. (1993). Particle-driven gravity currents. Journal of Fluid Mechanics, 250(1), 339-369. https://doi.org/10.1017/S002211209300148X

Buckee, C., Kneller, B., \& Peakall, J. (2001). Turbulence structure in steady, solute-driven gravity currents. In W. D. McCaffrey, B. C. Kneller, \& J. Peakall (Eds.), Particulate gravity currents, IAS Spec. Publ. (Vol. 31, pp. 173-187). Oxford: Blackwell. https://doi.org/ 10.1002/9781444304275.ch13

Cantero, M. I., Balachandar, S., Cantelli, A., Pirmez, C., \& Parker, G. (2009). Turbidity current with a roof: Direct numerical simulation of self-stratified turbulent channel flow driven by suspended sediment. Journal of Geophysical Research, 114, C03008. https://doi.org/ 10.1029/2008JC004978

Clark, J. D., Kenyon, N. H., \& Pickering, K. T. (1992). Quantitative analysis of the geometry of submarine channels: Implications for the classification of submarine fans. Geology, 20(7), 633-636. https://doi.org/10.1130/0091-7613(1992)020<0633:QAOTGO>2.3.CO;2

Cossu, R., \& Wells, M. G. (2010). Coriolis forces influence the secondary circulation of gravity currents flowing in large-scale sinuous submarine channel systems. Geophysical Research Letters, 37, L17603. https://doi.org/10.1029/2010GL044296

Cossu, R., \& Wells, M. G. (2012). A comparison of the shear stress distribution in the bottom boundary layer of experimental density and turbidity currents. European Journal of Mechanics - B/Fluids, 32, 70-79. https://doi.org/10.1016/j.euromechflu.2011.09.006

Curray, J. R., Emmel, F. J., \& Moore, D. G. (2002). The Bengal fan: Morphology, geometry, stratigraphy, history and processes. Marine and Petroleum Geology, 19(10), 1191-1223. https://doi.org/10.1016/S0264-8172(03)00035-7

De Leeuw, J., Eggenhuisen, J. T., \& Cartigny, M. J. (2016). Morphodynamics of submarine channel inception revealed by new experimental approach. Nature Communications, 7(1). https://doi.org/10.1038/ncomms10886 
Doronzo, D. M. (2013). Aeromechanic analysis of pyroclastic density currents past a building. Bulletin of Volcanology, 75(1), 684. https:// doi.org/10.1007/s00445-012-0684-z

Dorrell, R. M., Burns, A. D., \& McCaffrey, W. D. (2015). The inherent instability of leveed seafloor channels. Geophysical Research Letters, 42, 4023-4031. https://doi.org/10.1002/2015GL063809

Dorrell, R. M., Darby, S. E., Peakall, J., Sumner, E. J., Parsons, D. R., \& Wynn, R. B. (2013). Superelevation and overspill control secondary flow dynamics in submarine channels. Journal of Geophysical Research: Oceans, 118, 3895-3915. https://doi.org/10.1002/ jgrc. 20277

Dorrell, R. M., Darby, S. E., Peakall, J., Sumner, E. J., Parsons, D. R., \& Wynn, R. B. (2014). The critical role of stratification in submarine channels: Implications for channelization and long runout of flows. Journal of Geophysical Research: Oceans, 119, 2620-2641. https:// doi.org/10.1002/2014JC009807

Dorrell, R. M., Peakall, J., Sumner, E. J., Parsons, D. R., Darby, S. E., Wynn, R. B., et al. (2016). Flow dynamics and mixing processes in hydraulic jump arrays: Implications for channel-lobe transition zones. Marine Geology, 381, 181-193. https://doi.org/10.1016/j. margeo.2016.09.009

Eidsvik, K. J., \& Brørs, B. (1989). Self-accelerated turbidity current prediction based upon $(k-\varepsilon)$ turbulence. Continental Shelf Research, 9(7), 617-627. https://doi.org/10.1016/0278-4343(89)90033-2

Ellison, T. H., \& Turner, J. S. (1959). Turbulent entrainment in stratified flows. Journal of Fluid Mechanics, 6(03), 423-448. https://doi.org/ $10.1017 / \mathrm{S} 0022112059000738$

Garcia, M., \& Parker, G. (1993). Experiments on the entrainment of sediment into suspension by a dense bottom current. Journal of Geophysical Research, 98(C3), 4793-4807. https://doi.org/10.1029/92JC02404

Gauer, P., Kvalstad, T. J., Forsberg, C. F., Bryn, P., \& Berg, K. (2005). The last phase of the Storegga slide: Simulation of retrogressive slide dynamics and comparison with slide-scar morphology. In Ormen Lange-An integrated study for safe field development in the Storegga submarine area (pp. 171-178). Oxford: Elsevier. https://doi.org/10.1016/B978-0-08-044694-3.50018-4

Giorgio Serchi, F., Peakall, J., Ingham, D. B., \& Burns, A. D. (2011). A unifying computational fluid dynamics investigation on the river-like to river-reversed secondary circulation in submarine channel bends. Journal of Geophysical Research, 116, C06012. https://doi.org/ 10.1029/2010JC006361

Huang, H., Imran, J., \& Pirmez, C. (2005). Numerical model of turbidity currents with a deforming bottom boundary. Journal of Hydraulic Engineering, 131(4), 283-293. https://doi.org/10.1061/(ASCE)0733-9429(2005)131:4(283)

Imran, J., Islam, M. A., Huang, H., Kassem, A., Dickerson, J., Pirmez, C., \& Parker, G. (2007). Helical flow couplets in submarine gravity underflows. Geology, 35(7), 659-662. https://doi.org/10.1130/G23780A.1

Imran, J., Kassem, A., \& Khan, S. M. (2004). Three-dimensional modeling of density current. I. Flow in straight confined and unconfined channels. Journal of Hydraulic Research, 42(6), 578-590. https://doi.org/10.1080/00221686.2004.9628312

Imran, J., Khan, S. M., Pirmez, C., \& Parker, G. (2016). Froude scaling limitations in modeling of turbidity currents. Environmental Fluid Mechanics, 17(1), 159-186.

Islam, M. A., \& Imran, J. (2010). Vertical structure of continuous release saline and turbidity currents. Journal of Geophysical Research, 115, C08025. https://doi.org/10.1029/2009JC005365

Keevil, G. M., Peakall, J., Best, J. L., \& Amos, K. J. (2006). Flow structure in sinuous submarine channels: Velocity and turbulence structure of an experimental submarine channel. Marine Geology, 229(3-4), 241-257. https://doi.org/10.1016/j.margeo.2006.03.010

Kenyon, N. H., Amir, A., \& Cramp, A. (1995). Geometry of the younger sediment bodies of the Indus Fan. In Atlas of deep water environments (pp. 89-93). Netherlands: Springer. https://doi.org/10.1007/978-94-011-1234-5 16

Khripounoff, A., Vangriesheim, A., Babonneau, N., Crassous, P., Dennielou, B., \& Savoye, B. (2003). Direct observation of intense turbidity current activity in the Zaire submarine valley at $4000 \mathrm{~m}$ water depth. Marine Geology, 194(3-4), 151-158. https://doi.org/10.1016/S00253227(02)00677-1

Klaucke, I., Hesse, R., \& Ryan, W. B. F. (1998). Morphology and structure of a distal submarine trunk channel: The Northwest Atlantic MidOcean Channel between lat $53 \mathrm{~N}$ and 44 30' N. Geological Society of America Bulletin, 110(1), 22-34. https://doi.org/10.1130/00167606(1998) $110<0022: \mathrm{MASOAD}>2.3 . \mathrm{CO} ; 2$

Kneller, B., \& Buckee, C. (2000). The structure and fluid mechanics of turbidity currents: A review of some recent studies and their geological implications. Sedimentology, 47(s1), 62-94. https://doi.org/10.1046/j.1365-3091.2000.047s1062.x

Kneller, B., Nasr-Azadani, M. M., Radhakrishnan, S., \& Meiburg, E. (2016). Long-range sediment transport in the world's oceans by stably stratified turbidity currents. Journal of Geophysical Research: Oceans., 121, 8608-8620. https://doi.org/10.1002/2016JC011978

Kneller, B. C., Bennett, S. J., \& McCaffrey, W. D. (1999). Velocity structure, turbulence and fluid stresses in experimental gravity currents. Journal of Geophysical Research, 104(C3), 5381-5391. https://doi.org/10.1029/1998JC900077

Lofquist, K. (1960). Flow and stress near an interface between stratified liquids. The Physics of Fluids, 3(2), 158-175. https://doi.org/ $10.1063 / 1.1706013$

Meiburg, E., \& Kneller, B. (2010). Turbidity currents and their deposits. Annual Review of Fluid Mechanics, 42(1), 135-156. https://doi.org/ 10.1146/annurev-fluid-121108-145618

Menter, F. R. (1994). Two-equation eddy-viscosity turbulence models for engineering applications. AIAA Journal, 32(8), 1598-1605. https://doi.org/10.2514/3.12149

Middleton, G. V. (1966). Experiments on density and turbidity currents: I. Motion of the head. Canadian Journal of Earth Sciences, 3(4), 523-546. https://doi.org/10.1139/e66-038

Middleton, G. V. (1993). Sediment deposition from turbidity currents. Annual Review of Earth and Planetary Sciences, 21(1), 89-114. https://doi.org/10.1146/annurev.ea.21.050193.000513

Mohrig, D., \& Buttles, J. (2007). Deep turbidity currents in shallow channels. Geology, 35(2), 155-158. https://doi.org/10.1130/G22716A.1

Nakajima, T., \& Kneller, B. C. (2013). Quantitative analysis of the geometry of submarine external levees. Sedimentology, 60(4), $877-910$

Parker, G., Fukushima, Y., \& Pantin, H. M. (1986). Self-accelerating turbidity currents. Journal of Fluid Mechanics, 171(1), 145-181. https:// doi.org/10.1017/S0022112086001404

Parker, G., Garcia, M., Fukushima, Y., \& Yu, W. (1987). Experiments on turbidity currents over an erodible bed. Journal of Hydraulic Research, 25(1), 123-147. https://doi.org/10.1080/00221688709499292

Peakall, J., \& Sumner, E. J. (2015). Submarine channel flow processes and deposits: A process-product perspective. Geomorphology, 244, 95-120. https://doi.org/10.1016/j.geomorph.2015.03.005

Sequeiros, O. E. (2012). Estimating turbidity current conditions from channel morphology: A Froude number approach. Journal of Geophysical Research, 117, C04003. https://doi.org/10.1029/2011JC007201 
Sequeiros, O. E., Spinewine, B., Beaubouef, R. T., Sun, T., García, M. H., \& Parker, G. (2010). Characteristics of velocity and excess density profiles of saline underflows and turbidity currents flowing over a mobile bed. Journal of Hydraulic Engineering, 136(7), 412-433. https:// doi.org/10.1061/(ASCE)HY.1943-7900.0000200

Stagnaro, M., \& Pittaluga, M. B. (2014). Velocity and concentration profiles of saline and turbidity currents flowing in a straight channel under quasi-uniform conditions. Earth Surface Dynamics, 2(1), 167-180. https://doi.org/10.5194/esurf-2-167-2014

Straub, K. M., Mohrig, D., McElroy, B., Buttles, J., \& Pirmez, C. (2008). Interactions between turbidity currents and topography in aggrading sinuous submarine channels: A laboratory study. Geological Society of America Bulletin, 120(3-4), 368-385. https://doi.org/ 10.1130/B25983.1

Sumner, E. J., \& Paull, C. K. (2014). Swept away by a turbidity current in Mendocino submarine canyon, California. Geophysical Research Letters, 41, 7611-7618. https://doi.org/10.1002/2014GL061863

Sumner, E. J., Peakall, J., Parsons, D. R., Wynn, R. B., Darby, S. E., Dorrell, R. M., et al. (2013). First direct measurements of hydraulic jumps in an active submarine density current. Geophysical Research Letters, 40, 5904-5908. https://doi.org/10.1002/2013GL057862

Symons, W. O., Sumner, E. J., Paull, C. K., Cartigny, M. J., Xu, J. P., Maier, K. L., et al. (2017). A new model for turbidity current behavior based on integration of flow monitoring and precision coring in a submarine canyon. Geology, 45(4), 367-370. https://doi.org/10.1130/ G38764.1

Talling, P. J., Amy, L. A., \& Wynn, R. B. (2007). New insight into the evolution of large-volume turbidity currents: Comparison of turbidite shape and previous modelling results. Sedimentology, 54(4), 737-769. https://doi.org/10.1111/j.1365-3091.2007.00858.x

Talling, P. J., Paull, C. K., \& Piper, D. J. (2013). How are subaqueous sediment density flows triggered, what is their internal structure and how does it evolve? Direct observations from monitoring of active flows. Earth-Science Reviews, 125, 244-287. https://doi.org/10.1016/j. earscirev.2013.07.005

Wynn, R. B., Piper, D. J., \& Gee, M. J. (2002). Generation and migration of coarse-grained sediment waves in turbidity current channels and channel-lobe transition zones. Marine Geology, 192(1-3), 59-78.

Xu, J. P. (2010). Normalized velocity profiles of field-measured turbidity currents. Geology, 38(6), 563-566. https://doi.org/10.1130/ G30582.1 